\title{
ELICITATION OF THERAPEUTIC POTENTIAL AND OXIDATIVE STRESS ASSESSMENT OF FENUGREEK SPROUTS UNDER UV IRRADIATION
}

\author{
SARAN KUMAR GUPTA ${ }^{1}$, NAJNIN ISLAM ${ }^{1}$, CHANDRANI CHOUDHURI ${ }^{2}$, PALASH MANDAL ${ }^{{ }^{*}}$ \\ 1Plant Physiology and Pharmacognosy Research Laboratory, Department of Botany, University of North Bengal, Siliguri 734013, West \\ Bengal, India, 2Department of Botany, North Bengal St. Xavier's College, Rajganj 735134, Jalpaiguri, West Bengal, India \\ Email: nbubotanypm@gmail.com \\ Received: 13 Oct 2016 Revised and Accepted: 20 Mar 2017
}

\section{ABSTRACT}

Objective: To evaluate the effect of ultraviolet (UV) radiation on the therapeutical and oxidative stress status of fenugreek seedlings during the post-germination phase.

Methods: The seeds of Trigonella foenum-graecum L. were subjected to UV radiation of different wavelengths UV $254 \mathrm{~nm}$, UV $365 \mathrm{~nm}$ and the combination of $254 \mathrm{~nm}$ and $365 \mathrm{~nm}$ UV during the course of germination up to $96 \mathrm{~h}$. Free radicals scavenging activity, in vitro antidiabetic activity as well as total phenol (TPC) and flavonoid (TFC) contents were evaluated up to four days of germination stages. Analysis of total activities of superoxide dismutase (SOD), peroxidase, catalase and NADPH oxidase (NOX) was conducted using non-denaturing polyacrylamide gel electrophoresis along with histochemical detection of $\mathrm{H}_{2} \mathrm{O}_{2}$ and superoxide radical localisation, lipid peroxidation and plasma membrane integrity was also performed.

Results: Overall it was observed that the sprouts exposed to UV $365 \mathrm{~nm}$ exhibited a significant enhancement in free radical scavenging as well as antidiabetic activity at the $48 \mathrm{~h}$ stage of germination. Interestingly highest phenol and flavonol content were also stimulated at the same stage by UV $365 \mathrm{~nm}$. The effect of UV irradiation was evident on the localisation of $\mathrm{H}_{2} \mathrm{O}_{2}$ and superoxide radical. The on gel assay revealed that the total activities of the antioxidant enzymes were extensively elevated by UV irradiation.

Conclusion: The results suggest that the UV irradiation technology can be implemented for the enhancement of nutraceutical properties of sprouts also UV exposure helps in the induction of the antioxidant enzyme system which may be beneficial for oxidative stress management in plants during germination phases.

Keywords: Trigonella foenum-graecum, Antidiabetic activity, Antioxidant enzymes, Oxidative stress, Phenolic compounds, UV irradiation

(C) 2017 The Authors. Published by Innovare Academic Sciences Pvt Ltd. This is an open access article under the CC BY license (http://creativecommons.org/licenses/by/4.0/) DOI: http://dx.doi.org/10.22159/ijpps.2017v9i5.15647

\section{INTRODUCTION}

Since recent past years, seed sprouting technique is gaining more significance commercially all over the world. The sprouts being the initial phase of the growth and developmental process, their nutrient content is very high. Sprouts are a resource of the nutrients besides that sprouts are rich in phytochemicals, vitamins, minerals, enzymes and amino acids, all these are the most valuable compound meant for the human health. Sprouting also removes some anti-nutritive factors such as enzyme inhibitors from the seed that make sprouts safe for consumption. Sprouting in fenugreek is known to improve its soluble protein and fibre content and reduce the phytic, tannic acid and trypsin inhibitors [1].

Free radicals are released due to an imbalance in pro-oxidant/ antioxidant homoeostasis and also during cellular metabolism. These free radicals and reactive oxygen species (ROS) being very unstable, reacts with the biomolecules leading to inactivation of metabolic enzymes and damaging important cellular components, consequently causing several chronic diseases such as Alzheimer's disease, Parkinson's disease, atherosclerosis, pancreatic diseases, cancer, ageing and other neurological [2, 3].

These toxic effects of ROS and unstable free radicals can be mitigated by the counter action of some bioactive compounds such as polyphenols, ascorbic acid, carotene, glutathione etc. Such antioxidant defences are extremely important as they represent the direct removal of free radicals, thus providing maximal protection for the biological system from these chronic and degenerative diseases [4, 5]. Hyperglycemia, a disorder characterized by an abnormal excess of sugar level in the blood, has been found to be associated with the onset of type 2 diabetes mellitus and other cardiovascular complications $[6,7]$. Therefore the natural sources of antioxidant and anti-hyperglycaemic compounds are very important for consumption for better health management.

Fenugreek, Trigonella foenum-graecum L. is used as a traditional medicine since ancient times. It is commonly known as seed spice used to improve flavour, colour and taste of food. Fenugreek seed extract has antioxidant; anti-diabetic, anti-cataract, antitoxic and immune-modulatory activities [8].

Ultraviolet (UV) radiation despite of its deleterious impact on plant system including deoxyribonucleic acid (DNA) damage, mechanistic damage to photosynthetic apparatus and degradation of protein synthesis [9] has been positively implemented in various researchers with sublethal doses. Several reports have suggested that UV radiations have been successfully used in the extension of shelf life of fruits and vegetables. The application of UV treatment in several plant systems has resulted in enhancement of bioactive phytochemical content and quality composition [10].

Existing literature have suggested that UV radiation has been found to enhance the synthesis of bioactive components in various plant samples but till date, no research has been reported on the effect of UV radiation on the phytochemical content, antioxidant and antidiabetic property of fenugreek during post-germination phases. So the objective of this study was to evaluate the alteration in antioxidant activity, antidiabetic property and also the associated phytochemical contents of fenugreek sprouts in different germination phases elicited by UV irradiation.

\section{MATERIALS AND METHODS}

\section{Chemicals and reagents}

DPPH, ABTS, methanol, ferrozine, $\mathrm{FeCl}_{2}$, potassium ferricyanide, trichloroacetic acid, $\alpha$-amylase, DNSA, starch, sodium carbonate, $\rho$ - 
nitrophenyl $\alpha \mathrm{D}$-glucoside (pNPG), $\alpha$-glucosidase enzyme, quercetin, $\mathrm{AlCl}_{3}, \mathrm{NaOH}, \mathrm{NaNO}_{2}$, gallic, folin-ciocalteau, $\mathrm{FeCl}_{3}$, Evans blue, $\mathrm{CaCl}_{2}$, potassium sulphite, Schiff's reagent, nitroblue tetrazolium, potassium iodide, starch, acrylamide, N,N'-methylene-bis (acrylamide), potassium hydroxide, potassium dihydrogen phosphate, disodium hydrogen phosphate, sodium dihydrogen phosphate, EDTA, triton, riboflavin, TEMED, $\mathrm{H}_{2} \mathrm{O}_{2}$, benzidine, Tris, NADPH were purchased either from Sigma chemicals (USA) or Merck (India) of analytical grade.

\section{Elicitation process}

The seeds of Trigonella foenum-graecum (Methi-P. E. B) were purchased from National Seeds Corporation Limited, Beej Bhavan, Pusa Complex, New Delhi. The seeds were surface sterilized with $1 \%$ (v/v) sodium hypochlorite solution. The sterilized seeds were elicited with UV rays of different wavelength i.e., $254 \mathrm{~nm}$ for $10 \mathrm{~min}$, $365 \mathrm{~nm}$ for $10 \mathrm{~min}$ and both $254 \mathrm{~nm}$ and $365 \mathrm{~nm}$ in combination (COMB) for $5 \mathrm{~min}$ each. The dose applied were equal to $1.27 \mathrm{~kJ} \mathrm{~m}^{-2}$, $1.94 \mathrm{~kJ} \mathrm{~m}^{-2}$ and $1.61 \mathrm{~kJ} \mathrm{~m}^{-2}$ for $254 \mathrm{~nm}, 365 \mathrm{~nm}$ and combination respectively. Seeds were treated with UV radiation for 3 times a day with $8 \mathrm{~h}$ of the interval during the course of germination up to $4 \mathrm{~d}$. The untreated seeds were used as a control set. For UV exposure the fenugreek seeds were placed under a 6 watt germicidal UV lamp (VL-6. LC $254 \mathrm{~nm}$, Vilber Lourmat, France) at a distance of $5 \mathrm{~cm}$ from seeds. The intensity of irradiation was determined using a photoradiometer (HD2102.2; Delta OHM, Padova, Italy).

\section{Preparation of extract}

The sprouts of fenugreek of 4 different stages $(24 \mathrm{~h}, 48 \mathrm{~h}, 72 \mathrm{~h}$ and 96h) treated and untreated were crushed in mortar-pestle and processed through soxhlet extraction apparatus with methanol. The obtained extract was concentrated to a definite concentration of $1 \mathrm{~g} / \mathrm{ml}$ using a vacuum rotary evaporator at temperature $\leq 45^{\circ} \mathrm{C}$ and stored in brown bottles for further experimental analysis.

\section{DPPH based free radical scavenging activity}

The radical scavenging activity of the extracts was measured by 2 , 2-diphenyl-1-picrylhydrazyl (DPPH) method [11]. The reaction mixture containing $1.8 \mathrm{ml}$ of $0.1 \mathrm{mmol}$ DPPH and $0.2 \mathrm{ml}$ extracts were incubated for $30 \mathrm{~min}$ and the absorbance was recorded at $517 \mathrm{~nm}$.

\section{ABTS+radical cation(s) decolorization assay}

The analysis of 2,2'-azinobis-(3-ethybenzthiazoline sulfonic acid) (ABTS+)radical cation(s) scavenging activity was determined by spectrophotometric method [12]. This method is based on the ability of antioxidants to quench the $\mathrm{ABTS}^{+}$radical cation, a blue/green chromophore with characteristic absorption at 734 nm.

\section{Metal chelating activity}

The chelating activity of the extracts for ferrous ions $\mathrm{Fe}^{2+}$ was measured spectrophotometrically [13]. To $0.4 \mathrm{ml}$ of methanol extract, $1.6 \mathrm{ml}$ of methanol was diluted and mixed with $0.04 \mathrm{ml}$ of $\mathrm{FeCl}_{2}(2 \mathrm{mmol})$. After $30 \mathrm{sec}, 0.8 \mathrm{ml}$ ferrozine $(5 \mathrm{mmol})$ was added. After $10 \mathrm{~min}$ at room temperature, the absorbance of the $\mathrm{Fe}^{2+}$ Ferrozine complex was measured at $562 \mathrm{~nm}$.

\section{Ferric reducing antioxidant power (FRAP) assay}

The reducing antioxidant power of plant methanolic extracts was determined by the standard method [14]. Different concentrations of $1 \mathrm{ml}$ of fruit extracts were mixed with phosphate buffer $(2.5 \mathrm{ml}, 0.2 \mathrm{M}, \mathrm{pH}$ 6.6) and potassium ferricyanide $\left[\mathrm{K}_{3} \mathrm{Fe}(\mathrm{CN})_{6}\right] \quad(2.5 \mathrm{ml}, 1 \%)$. The mixture was incubated at $50^{\circ} \mathrm{C}$ for $20 \mathrm{~min}$. Then, $2.5 \mathrm{ml}$ of trichloroacetic acid $(10 \% \mathrm{w} / \mathrm{v})$ was added to the mixture, which was then centrifuged for $10 \mathrm{~min}$ at $3000 \mathrm{rpm}$. The upper layer of solution $(2.5 \mathrm{ml})$ was mixed with distilled water $(2.5 \mathrm{ml})$ and $\mathrm{FeCl}_{3}(0.5$ $\mathrm{ml}, 0.1 \%$ ). The absorbance was measured at $700 \mathrm{~nm}$ against a blank using UV-VIS spectrophotometer (Systronics, 2201, India).

\section{Total phenol content}

Total phenol content of plant extracts was determined by folinciocalteau method [15]. $1 \mathrm{ml}$ of the various methanolic extracts was mixed in a test tube containing $1 \mathrm{ml}$ of $95 \%$ ethanol, $5 \mathrm{ml}$ of distilled water and $0.5 \mathrm{ml}$ of $50 \%$ folin-ciocalteau reagent. The resultant mixture was allowed to react for $5 \mathrm{~min}$ and $1 \mathrm{ml}$ of $5 \%$ $\mathrm{Na}_{2} \mathrm{CO}_{3}$ was added. It was mixed thoroughly and placed in the dark for $1 \mathrm{~h}$. Finally, the absorbance of the coloured reaction product was measured at $765 \mathrm{~nm}$ against the reagent blank. The total phenolic content was expressed as $\mathrm{mg}$ of gallic acid equivalent (GAE) per gram fresh weight (fw).

\section{Total flavonoid content}

The flavonoid content was measured following a standard spectrophotometric method [16]. One ml of methanolic extracts was diluted with water $(4 \mathrm{ml})$ in a $10 \mathrm{ml}$ volumetric flask. Initially, $5 \%$ $\mathrm{NaNO}_{2}$ solution $(0.3 \mathrm{ml})$ was added to each volumetric flask; at 5 min, $10 \% \mathrm{AlCl}_{3}(0.3 \mathrm{ml})$ was added; and then after $6 \mathrm{~min}, 1 \mathrm{M} \mathrm{NaOH}$ $(2 \mathrm{ml})$ was added. After addition of distilled water $(2.4 \mathrm{ml})$ absorbance was read at $510 \mathrm{~nm}$. The total flavonoid content in different extracts was calculated as quercetin equivalent (QE) per gm fresh weight.

\section{$\alpha$-glucosidase inhibitory activity}

The $\alpha$-glucosidase inhibitory activity was determined following the protocol suggested by Ghosal and Mandal [17]. A volume of $250 \mu \mathrm{l}$ of plant extract was reacted with $500 \mu \mathrm{l}$ of the $\alpha$-glucosidase enzyme $(0.1 \mathrm{U} / \mathrm{ml}$ in $0.1 \mathrm{M}$ potassium phosphate buffer, $\mathrm{pH} 6.9)$ in test tubes and incubated at $37{ }^{\circ} \mathrm{C}$ for about half an hour. After incubation, 250 $\mu \mathrm{l}$ of $\rho$-nitrophenyl $\alpha \mathrm{D}$-glucoside (pNPG) $(5 \mathrm{mmol}$ in $0.1 \mathrm{M}$ phosphate buffer, $\mathrm{pH}$ 6.9) was added to each test tube and the reaction mixture was kept for $30 \mathrm{~min}$ at $37^{\circ} \mathrm{C}$. To the above reaction mixture $300 \mu \mathrm{l}$ of sodium carbonate solution $(100 \mathrm{mmol})$ was added and incubated again for $20 \mathrm{~min}$ at $37{ }^{\circ} \mathrm{C}$. The absorbance was recorded at $405 \mathrm{~nm}$ and compared to the control in which $250 \mu \mathrm{l}$ of buffer was added instead of plant extract. The $\alpha$-glucosidase inhibitory activity was evaluated by measuring the release of $\rho$ nitrophenol from pNPG.

\section{$\alpha$-amylase inhibitory activity}

The $\alpha$-amylase inhibitory potential of the sample was estimated by spectrophotometric method [17]. At first $500 \mu \mathrm{l}$ of extract was reacted with $500 \mu \mathrm{l}$ of $\alpha$-amylase solution $(0.5 \mathrm{mg} / \mathrm{ml}$ in $0.02 \mathrm{M}$ sodium phosphate buffer, $\mathrm{pH} 6.9$ ) and incubated at $37^{\circ} \mathrm{C}$ for $5 \mathrm{~min}$. After incubation, $500 \mu \mathrm{l}$ of starch solution $(1 \%, \mathrm{w} / \mathrm{v})$ was added and further kept undisturbed for $10 \mathrm{~min}$ at room temperature. The reaction was terminated by addition of $1 \mathrm{ml}$ of 3,5-dinitrosalicylic acid (DNSA) reagent and the test tubes were placed in a hot water bath till the colour of reaction mixture changed to orange-red. After that, the reaction mixture was cooled and diluted with distilled water up to $5 \mathrm{ml}$. The generation of maltose was determined by recording the $O D$ value at $540 \mathrm{~nm}$.

\section{Histochemical detection}

For detection of hydrogen peroxide localisation in the roots, the seedlings were kept submerged for about $45 \mathrm{~min}$ in potassium iodide $(0.1 \mathrm{M}) /$ starch $(4 \% \mathrm{w} / \mathrm{v})$ reagent [18]. The histochemical detection of superoxide localisation, lipid peroxidation and plasma membrane integrity was conducted by the method followed by Kaur et al. [19]. For detection of superoxide anion radical the seedlings were submerged in $50 \mathrm{mmol}$ phosphate buffer (pH 7.5$)$ containing $(0.05 \% \mathrm{w} / \mathrm{v})$ nitroblue tetrazolium (NBT) for $20 \mathrm{~min}$ in presence of light and then the roots were placed in ethanol for terminating the reaction. For detection of lipid peroxidation, the fenugreek roots were placed in Schiff's reagent until the coloured stain developed on the roots. The extra stain imparted by the reagent was removed using potassium sulphite solution $(0.5 \% \mathrm{w} / \mathrm{v})$ in $0.05 \mathrm{M} \mathrm{HCl}$. For detection of the integrity of plasma membrane, the roots were stained using Evans blue solution $(0.025 \% \mathrm{w} / \mathrm{v}$ in $100 \mathrm{mmol}$ $\mathrm{CaCl}_{2}$ ) for about half an hour and then the stained roots were rinsed thrice with distilled water for removal of extra stain. All the above-stained roots were photographed using Nikon SLR camera (Model: D3200). 


\section{Detection of isozyme pattern by gel electrophoresis}

The tissues were homogenized with ice-cold $50 \mathrm{mmol}$ potassium phosphate buffer ( $\mathrm{pH} 7.0$ ) including 1\% polyvinyl pyrrolidone, 2 mmol ethylene diamine tetraacetic acid (EDTA) and $0.1 \%$ triton. The homogenate was centrifuged at $10,000 \mathrm{~g}$ for $20 \mathrm{~min}$ at $4{ }^{\circ} \mathrm{C}$ and the obtained supernatant was used for further detection of isoenzymes.

The isozymes of superoxide dismutase (SOD; EC 1.15.1.1), peroxidase (POD; EC 1.11.1.7) and NADPH oxidase (NOX; EC 1.6.3.1) were separated on discontinuous polyacrylamide gels (composed of $5 \%$ stacking gel and $10 \%$ resolving gel) and for catalase (CAT; EC 1.11.1.6) (4\% stacking gel and 8\% resolving gel) under non-denaturing conditions. Proteins were electrophoresed at $4{ }^{\circ} \mathrm{C}$ and $80 \mathrm{~V}$ in the stacking gel followed by $120 \mathrm{~V}$ in the resolving gel.

The isozyme pattern of superoxide dismutase activity was detected on gel as described by Pereira et al., [20]. The gels were rinsed in distilled water and incubated in an assay mixture containing $0.05 \mathrm{M}$ potassium phosphate buffer ( $\mathrm{pH} 7.8)$, EDTA $(1 \mathrm{mmol})$, riboflavin (0.05 mmol), nitroblue tetrazolium $(0.1 \mathrm{mmol})$ and $0.3 \% \mathrm{~N}, \mathrm{~N}, \mathrm{~N}^{\prime}, \mathrm{N}^{\prime}-$ tetramethyl-ethylenediamine (TEMED) in the dark condition for 30 min at room temperature. After incubation, the gels were again rinsed with distilled water and then illuminated on a light box until the colourless bands of SOD appeared against a purple-stained gel background.

For detection of catalase isoforms, gels were soaked in $50 \mathrm{mmol}$ potassium-phosphate buffer ( $\mathrm{pH} 7.0)$ and then in the same buffer containing $5 \mathrm{mmol} \mathrm{H}_{2} \mathrm{O}_{2}$. After incubation, gels were rinsed with distilled water and stained in a reaction mixture composed of $1 \%$ potassium ferricyanide and $1 \%$ ferric chloride [21].
For peroxidase isoforms, the gels were soaked for $20 \mathrm{~min}$ in $0.2 \mathrm{M}$ acetate buffer (pH 5.5) with $5 \mathrm{mmol}$ benzidine and $5 \mathrm{mmol} \mathrm{H}_{2} \mathrm{O}_{2}$ [22]. For NOX isozymes, the gels were soaked in gel staining solution containing NBT $(0.5 \mathrm{mg} / \mathrm{ml})$ and $134 \mu \mathrm{M}$ NADPH in $10 \mathrm{mmol}$ Tris buffer, $\mathrm{pH} 7.4$ [23].

\section{Statistical analysis}

Each experiment was performed in triplicate. The software package, MS Excel 2007 (Microsoft, Redmond, WA, USA) was used for comparing the antioxidant and antidiabetic attributes of different stages of the fenugreek sprouts. The different group means were compared by Duncan's Multiple Range Test and differences at $p<0.05$ was considered significant in all cases.

\section{RESULTS}

\section{Phytochemical quantification}

For phytochemical analysis, total phenol and flavonol content was determined. The total phenol and flavonol content of fenugreek sprouts was estimated for $4 \mathrm{~d}$ of germination. The highest stimulation was observed at the $48 \mathrm{~h}$ stage for control as well as those subjected to UV exposure. Among the different wavelength of UV light applied, the sprouts treated with UV 365 $\mathrm{nm}$ exhibited the highest phenolic content which was $15 \%$ higher than control (fig. 1A). From the estimation of flavonol content, a gradual increase in the flavonol content was observed towards germination time. The maximum flavonol stimulation was observed for the sprouts treated with UV $254 \mathrm{~nm}$ which was about $50 \%$ greater than control at $72 \mathrm{~h}$ stage; UV $365 \mathrm{~nm}$ was found to enhance the highest flavonol content at $48 \mathrm{~h}(41 \%)$ and $96 \mathrm{~h}(34 \%)$ and combined exposure enhanced $56 \%$ of flavonol content at $24 \mathrm{~h}$ of germination (fig. 1B).
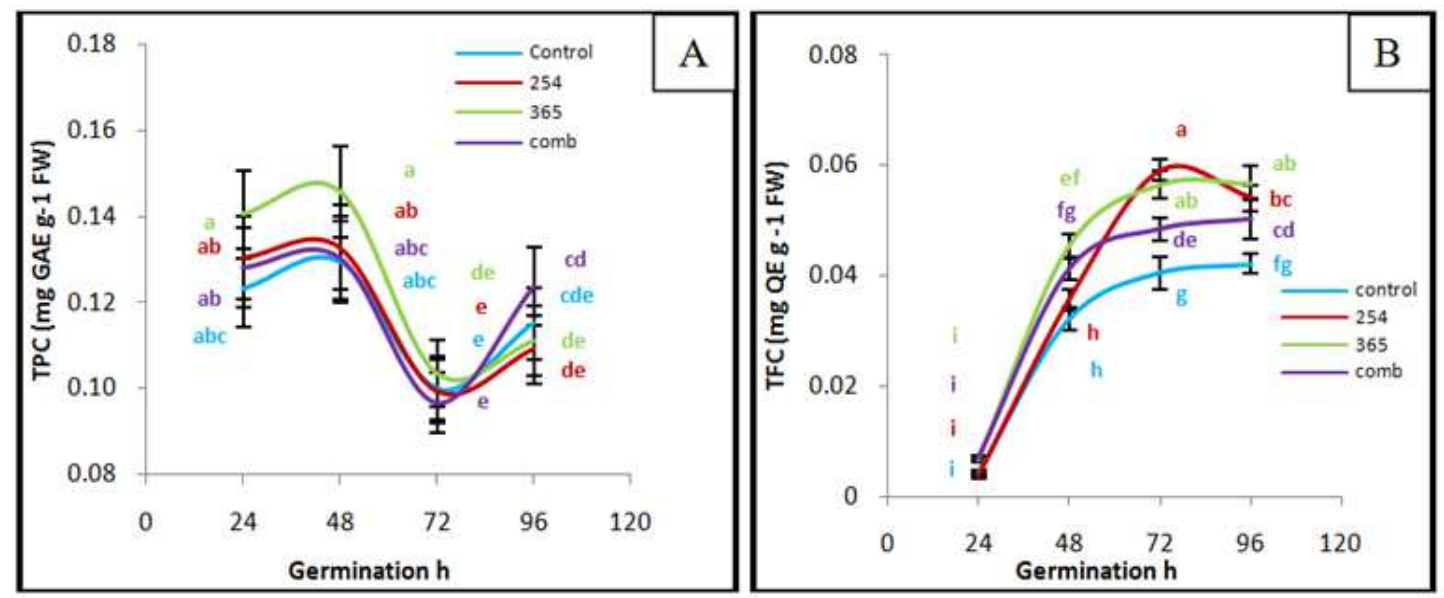

Fig. 1: A) Total phenol content and B) total flavonol content of the fenugreek sprouts of $24 \mathrm{~h}, 48 \mathrm{~h}, 72 \mathrm{~h}$ and $96 \mathrm{~h}$ stage, untreated and treated with $U V$ radiation of wavelength $254 \mathrm{~nm}, 365 \mathrm{~nm}$ and combined $(254 \mathrm{~nm}+365 \mathrm{~nm})$. Results are represented as mean $\pm S E M$, $n=3$. Values with different letters $(a, b, c$ etc) are significantly $(P<0.05)$ different from each other by Duncan's multiple range test (DMRT)

\section{Free radical scavenging activity}

DPPH and ABTS assay is widely used to evaluate the free radical scavenging activity of different plant materials. In the case of DPPH assay, extract having lowest $\mathrm{IC}_{50}$ value possessed higher scavenging activity. In the present experiment $48 \mathrm{~h}$ seedlings exhibited the best activity compared to the other germination stages and the seedlings treated with UV $254 \mathrm{~nm}$ showed the lowest $\mathrm{IC}_{50}$ value ( $\left.34.73 \mathrm{mg} \mathrm{ml}^{-1}\right)$ followed by UV $365 \mathrm{~nm}\left(47.95 \mathrm{mg} \mathrm{ml}^{-1}\right)$ and combination of both $(65.79$ $\left.\mathrm{mg} \mathrm{ml}^{-1}\right)$ also showed better activity than control set $\left(77.9 \mathrm{mg} \mathrm{ml}^{-1}\right)$. Free radical scavenging activity of seedlings for DPPH has increased up to

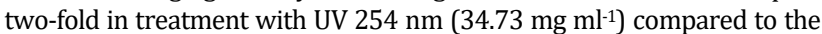
control $\left(77.9 \mathrm{mg} \mathrm{ml}^{-1}\right)$ seedlings at $48 \mathrm{~h}$ stage (fig. $2 \mathrm{~A}$ ). A similar trend of the result was observed in the $\mathrm{ABTS}^{+}$assay with enhancement of antioxidant property by UV treatment. Here the sprouts of the 48h stage showed best $\mathrm{IC}_{50}$ values than other stages. The lowest IC $\mathrm{C}_{50}$ values i.e. best activity was shown by the sprouts (fig. 2B) with UV $365 \mathrm{~nm}$ treatment $\left(16.3 \mathrm{mg} \mathrm{ml}^{-1}\right)$ followed by UV $254 \mathrm{~nm}\left(19.36 \mathrm{mg} \mathrm{ml}^{-1}\right)$ and combination of both $\left(29.89 \mathrm{mg} \mathrm{ml}^{-1}\right)$ and in contrast, the highest value was observed in control set (30.8 $\left.\mathrm{mg} \mathrm{ml}^{-1}\right)$. FRAP results also exhibited increased in the reducing activity of the sprouts treated with UV light (fig. 2C).

However, the best result was obtained from the seedlings treated with $365 \mathrm{~nm}$ which showed consistently enhanced activity till $96 \mathrm{~h}$ of germination time. Similar to DPPH and ABTS assay the result of metal chelating capacity also showed that the chelation capacity was enhanced best at the $48 \mathrm{~h}$ stage than other germination stages (fig. 2D). 

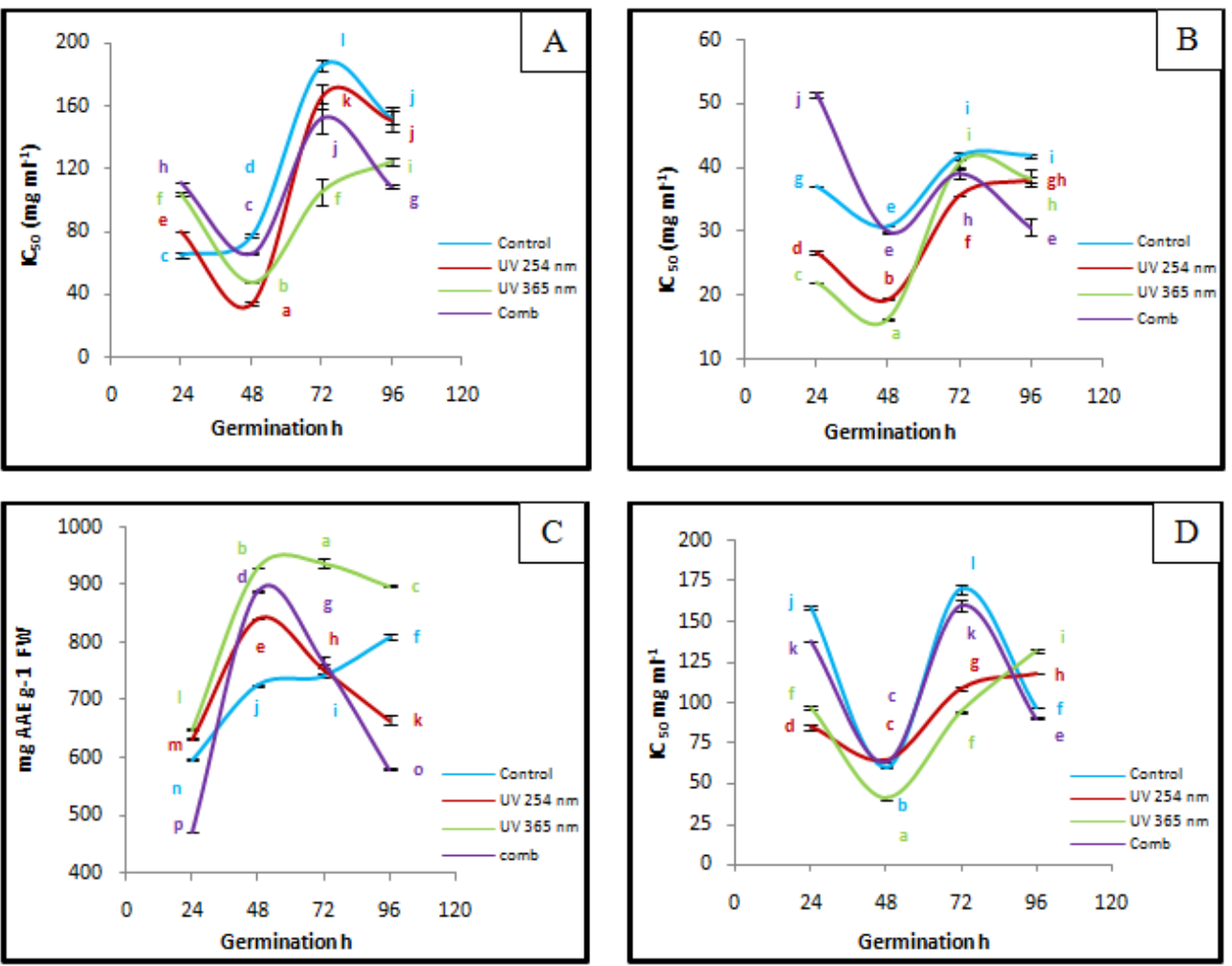

Fig. 2: A) DPPH and B) ABTS radical scavenging, C) reducing power and D) metal chelating activity of the fenugreek sprouts of $24 \mathrm{~h}, 48 \mathrm{~h}$, $72 \mathrm{~h}$ and $96 \mathrm{~h}$ stage, untreated and treated with $U V$ radiation of wavelength $254 \mathrm{~nm}, 365 \mathrm{~nm}$ and combined $(254 \mathrm{~nm}+365 \mathrm{~nm})$. Results are represented as mean \pm SEM, $n=3$. Values with different letters $(a, b, c$ etc) are significantly $(P<0.05)$ different from each other by Duncan's multiple range test (DMRT)

\section{In vitro antidiabetic activity}

For in vitro antidiabetic activity, the capacity of the extract to inhibit the activity of two key enzymes $\alpha$-glucosidase and $\alpha$-amylase was estimated. The inhibition capacity of the sprouts was expressed in terms of $\mathrm{IC}_{50}$ values. The results revealed that the fenugreek sprouts have potential anti-diabetic property and interestingly it was also observed that the UV irradiation resulted in enhancement of this activity in fenugreek sprouts. Both the $\alpha$-glucosidase and $\alpha$-amylase inhibition capacity was best enhanced by UV $365 \mathrm{~nm}$ at $48 \mathrm{~h}$ stage though at $24 \mathrm{~h}$ and $72 \mathrm{~h}$ stage the activity was considerably increased in comparison to other treatments and the control set (fig. 3).

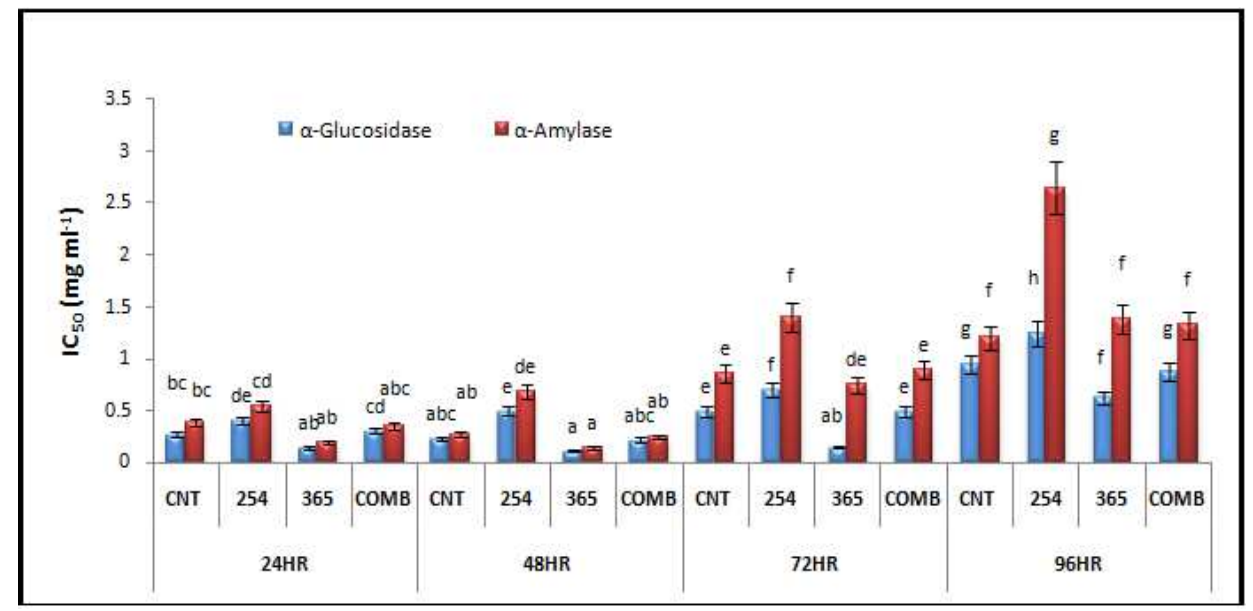

Fig. 3: In vitro $\alpha$-glucosidase and $\alpha$-amylase inhibitory activity of the fenugreek sprouts of $24 \mathrm{~h}, 48 \mathrm{~h}, 72 \mathrm{~h}$ and $96 \mathrm{~h}$ stage, untreated and treated with UV radiation of wavelength $254 \mathrm{~nm}, 365 \mathrm{~nm}$ and combined set $(254 \mathrm{~nm}+365 \mathrm{~nm})$. Results are represented as mean $\pm S E M$, $n=3$. Values with different letters $(a, b, c$ etc) are significantly $(P<0.05)$ different from each other by Duncan's multiple range test (DMRT) CNT: Control; 254: $254 \mathrm{~nm}$; 365: $365 \mathrm{~nm}$; COMB: Combination of $254 \mathrm{~nm}$ and $365 \mathrm{~nm}$

\section{Histochemical analysis}

Histochemical analysis was performed to examine the site of localisation of two highly reactive radicals namely superoxide anion and hydrogen peroxide as well as to determine the degree of lipid peroxidation and plasma membrane integrity of fenugreek seedlings. The $\mathrm{KI}$-starch reagent was used to detect the $\mathrm{H}_{2} \mathrm{O}_{2}$ localisation which imparted blackish stain at the $\mathrm{H}_{2} \mathrm{O}_{2}$ localised 
region. The study revealed that the localisation of $\mathrm{H}_{2} \mathrm{O}_{2}$ molecule was much higher in the seedlings exposed to the UV irradiation than the control one as evidenced by the stain imparted by KI-starch reagent (fig. 4A). For detection of superoxide anion in the tissue, nitro blue tetrazolium chloride solution was used as staining reagent which imparted bluish-black stain. It was observed that UV exposed roots were stained much darker than the control set, thus indicating higher $\mathrm{O}_{2}$-localisation (fig. 4B).
The roots were stained with Schiff's reagent for determining lipid peroxidation as indicated by pink colour. The roots treated with UV radiation exhibited a higher degree of lipid peroxidation thus indicating the oxidative stress created by UV light (fig. 4C). In the case of the plasma membrane integrity similar trend was observed; roots subjected to UV light coloured much darker blue stain with Evan's blue reagent (fig. 4D) thus exhibiting a higher degree of disintegration of the plasma membrane.

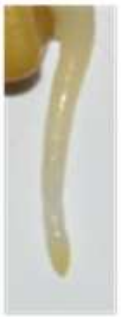

CONTROL

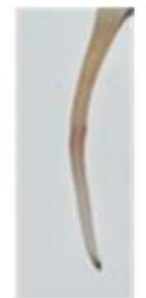

CONTROL

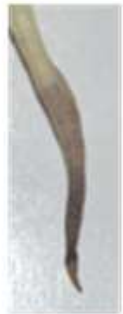

UV $254 \mathrm{~nm}$

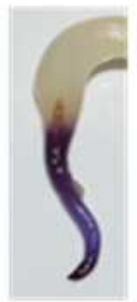

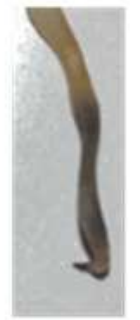

UV $365 \mathrm{~nm}$

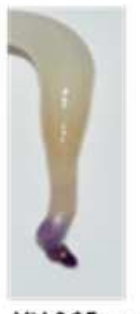

UV $365 \mathrm{~nm}$

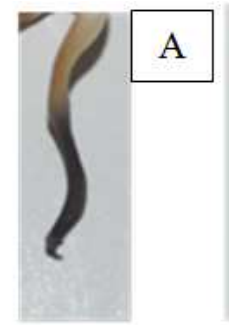

COMB

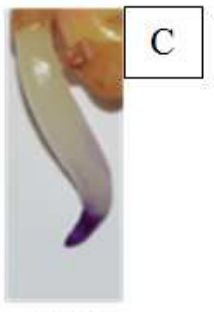

COMB

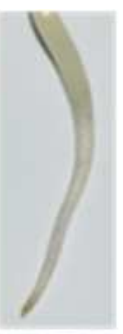

CONTROL

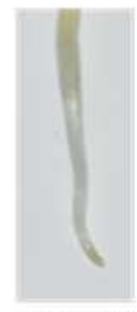

CONTROL

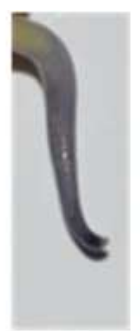

UV $254 \mathrm{~nm}$

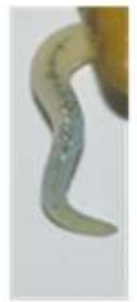

UV $254 \mathrm{~nm}$

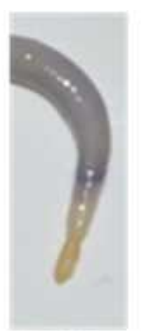

UV $365 \mathrm{~nm}$

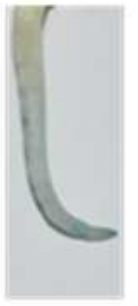

UV $365 \mathrm{~nm}$
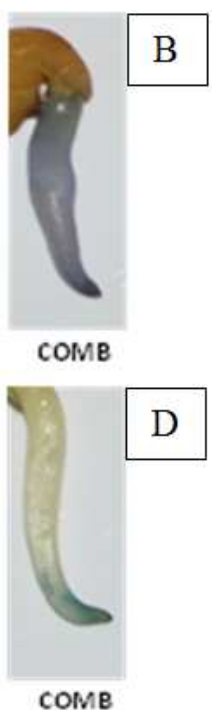

Fig. 4: Histochemical detection showing the effect of $\mathrm{UV}$ exposure on A) $\mathrm{H}_{2} \mathrm{O}_{2}$ localisation B) superoxide localisation C) lipid peroxidation and D) plasma membrane Integrity of the fenugreek seedlings

\section{On gel assay of antioxidative enzymes}

The activity of three different antioxidant enzymes namely superoxide dismutase, catalase and peroxidase were determined by native polyacrylamide gels. On determining SOD activity, five isoforms of SOD was detected in the fenugreek sprouts (fig. 5A). The patterns of the isozymes were different for the control and the UV treated seedlings. The seedlings treated with UV $254 \mathrm{~nm}$ did not show a significant change in the activity of the isozymes except for isozyme-II. However, UV $365 \mathrm{~nm}$ and combination $(254 \mathrm{~nm}+365$ $\mathrm{nm}$ ) exhibited a remarkable increase in the intensity of three isoforms-I, II and III, also a slight increase in the isoforms-IV and V thus indicating an increase in the SOD activity by UV irradiation. The relative densities of each SOD isoforms are represented in the fig. $5 \mathrm{~B}$ where the increase in the SOD activity was evident. For catalase, only one isoform were detected and here too the catalase band with greater intensity was found in the sprouts subjected to UV exposure except for UV $254 \mathrm{~nm}$ (fig. 6A), thus confirming an increase in catalase activity. The relative density of catalase isozyme is represented in the fig. 6B. For peroxidase also, only single isozyme was found with greater intensity of the band of the sprout treated with UV radiation except for UV $254 \mathrm{~nm}$ (fig. 7A). The relative density of peroxidase isozyme is represented in the fig. 7B. Another important enzyme NOX was also assayed by native polyacrylamide gels.

As a result, five isoforms of NOX was detected in the fenugreek seedlings (fig. 8A). The exposure with UV $365 \mathrm{~nm}$ resulted in enhanced activity in all the five isoforms, UV $254 \mathrm{~nm}$ also enhanced the activity of all isoforms except in isoforms-II the activity was slightly declined and the combined exposure resulted in a higher intensity of all other isozymes except a marginal decrease in isozyme-V. The relative density of NOX isozyme is represented in the fig. 8B.
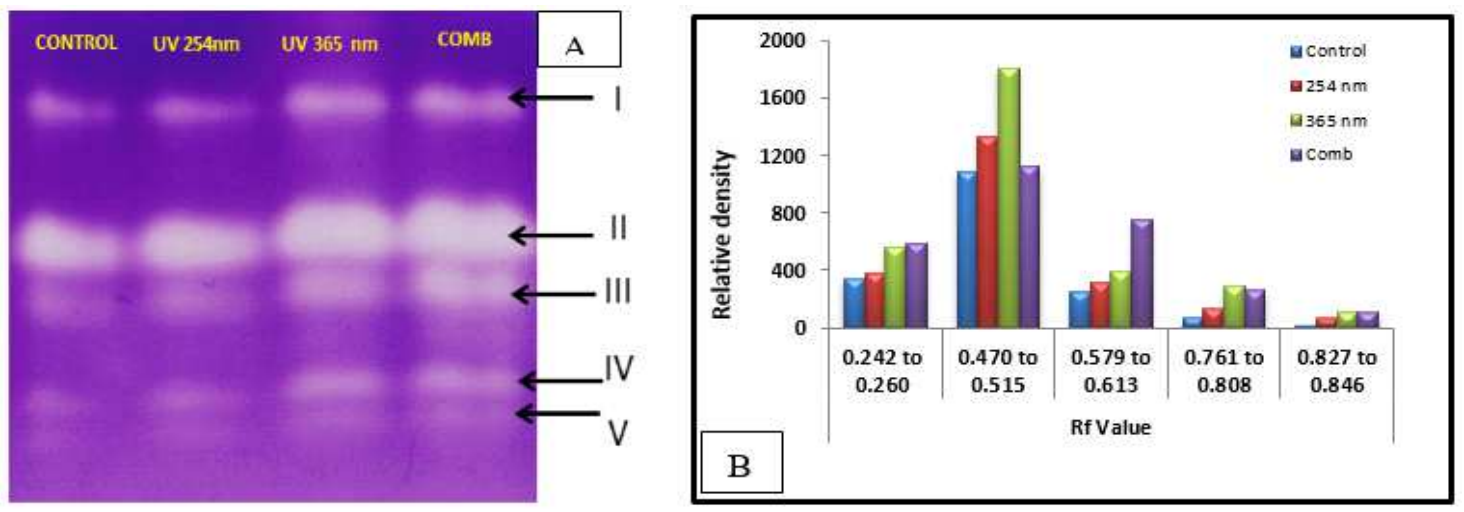

Fig. 5: Effect of UV exposure on the SOD activity of the fenugreek seedlings. A) On gel visualisation of SOD activity of treated and untreated seedlings, the arrows show the band corresponding to isoforms. B) The relative density of the SOD isoforms as detected by Image lab (Version 5.1, BIORAD) software 

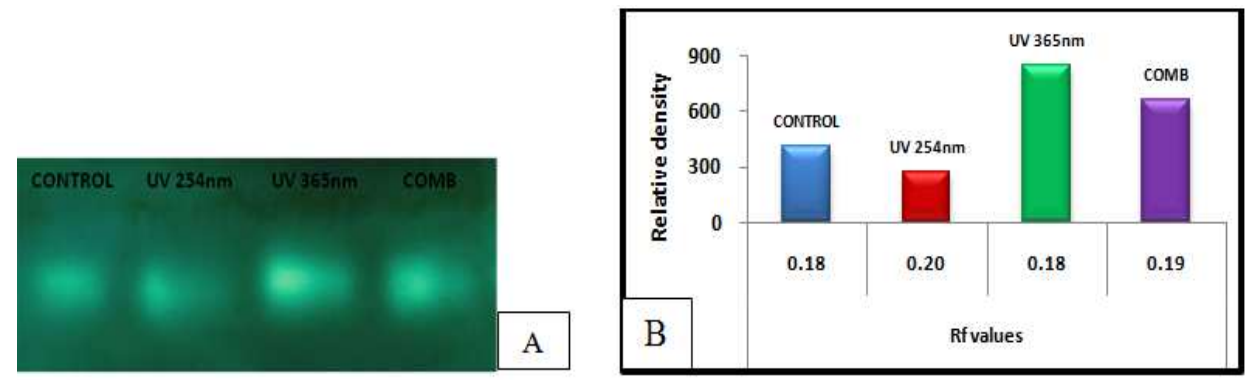

Fig. 6: Effect of UV exposure on the CAT activity of the fenugreek seedlings. A) On gel visualisation of CAT activity of treated and untreated seedlings. B) The relative density of the CAT isoforms as detected by Image lab (Version 5.1, BIORAD) software

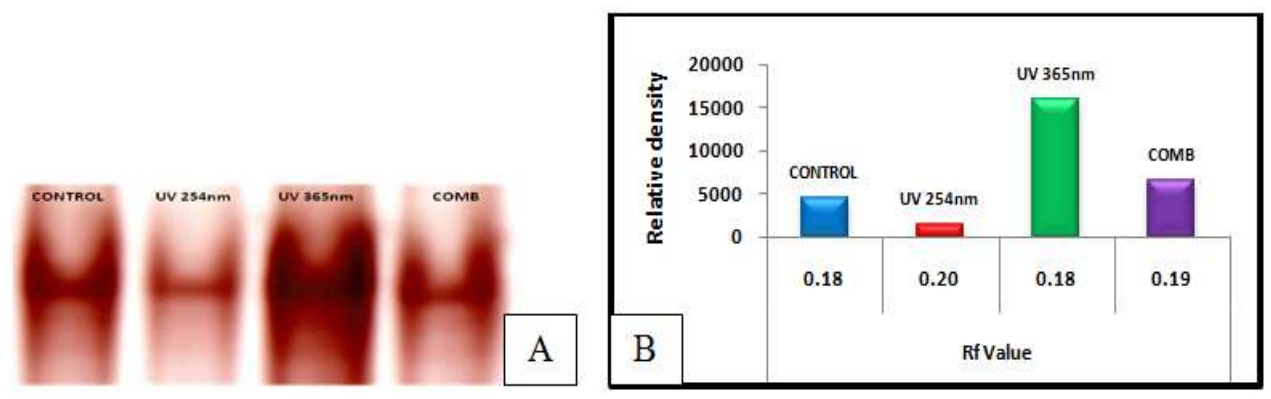

Fig. 7: Effect of UV exposure on the POD activity of the fenugreek seedlings. A) On gel visualisation of POD activity of treated and untreated seedlings. B) The relative density of the POD isoforms as detected by Image lab (Version 5.1, BIORAD) software
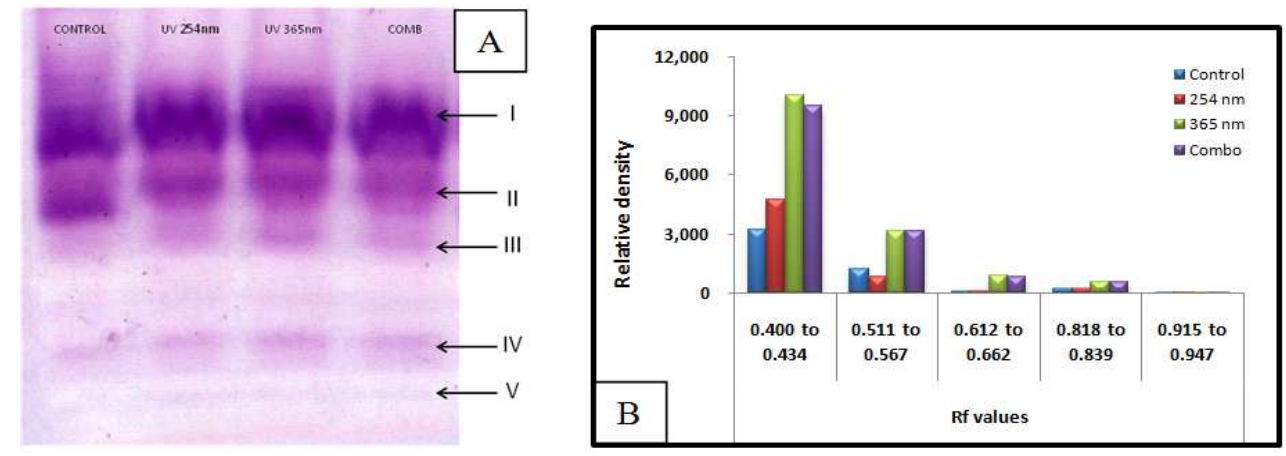

Fig. 8: Effect of UV exposure on the NOX activity of the fenugreek seedlings. A) On gel visualisation of NOX activity of treated and untreated seedlings, the arrows show the band corresponding to isoforms. B) The relative density of the NOX isoforms as detected by Image lab (Version 5.1, BIORAD) software

Table 1: Pearson correlation coefficients between various phytochemical attributes and antioxidant activity of fenugreek sprouts of different developmental phase

\begin{tabular}{|c|c|c|c|c|c|c|c|}
\hline & DPPH & ABTS & RP & MC & TPC & TFC & $\alpha$-glu \\
\hline ABTS & $0.653^{* *}$ & & & & & & \\
\hline $\mathrm{RP}$ & -0.132 & -0.298 & & & & & \\
\hline $\mathrm{MC}$ & $0.738^{* *}$ & $0.547^{*}$ & -0.349 & & & & \\
\hline TPC & $-0.745^{* *}$ & $-0.643^{* *}$ & -0.099 & $-0.516^{*}$ & & & \\
\hline TFC & 0.350 & 0.052 & $0.659^{* *}$ & -0.061 & -0.494 & & \\
\hline$\alpha$-glu & $0.562^{*}$ & 0.290 & -0.168 & 0.179 & -0.429 & 0.372 & \\
\hline$\alpha$-amy & $0.607^{*}$ & 0.337 & -0.039 & 0.251 & $-0.588^{*}$ & $0.517^{*}$ & $0.924^{* *}$ \\
\hline
\end{tabular}

fig. in bold indicate significant correlation; $(*, * *)=$ significant at $\mathrm{p}<0.05$ or 0.01 , respectively

\section{DISCUSSION}

The health benefits of phenolics have been widely reported by various workers. In human beings, phenolic compounds are known to exhibit potential antioxidant property, which is considered to be actively involved in the prevention of oxidative stress-mediated diseases and cardiac disorders. The theory of natural product chemistry suggests that most of the UV-absorbing factors are the active molecules produced by the plants in the form of secondary metabolites [24].

This implies that UV irradiation technology can be implemented in the enhancement of the production of these bioactive molecules for further enrichment of the nutraceutical properties of plant samples. 
In the present study, a significant increase in the phenol content of seedlings exposed to UV radiation was found when compared to that of the control set. Similarly, it was observed that phenolic compounds were increased in broccoli (UV-C) and Withania somnifera (UV-B) after exposure to UV radiation [25].

It has been reported that several defensive strategies have been developed by plants to cope with UV radiation. The accumulation of UV-B protective components such as phenols and flavonoids synthesized during phenylpropanoid pathway helps in attenuating the impact of UV radiation [26]. Hence the gradual increase in the flavonoid content at a higher rate in the UV treated seedlings than that of control seedlings can be explained by the higher accumulation of flavonoids as a defence mechanism in response to UV exposure. Our findings are in agreement with that of GonzalezAguilar et al. [27] who reported an increase in flavonoid content in mango, on exposure to UV radiation. Nowadays, flavonoids have gained considerable interest as they are found to be very effective contributors involved in protection against cardiovascular disorder by mitigating the oxidation of LDL as well as prevention of several other degenerative diseases [28]. However, these bioactive compounds (flavonoids) are considered to be absorbed in trace amounts in vivo; thus, there is a general tendency to either increase the consumption or enhance the flavonoid content of plant sources, as this can help in increasing the intake of these essential bioactive compounds and antioxidants.

$\mathrm{DPPH}$, a free radical is used as a simple and economical molecule to determine the antiradical activity of the sample. This method is widely implemented to evaluate the potential of a compound to act as efficient free radical scavengers or hydrogen donors [11]. The antioxidant activity of the fenugreek sprouts was determined by the ability to scavenge the DPPH radical in the reaction mixture. The scavenging effect of the sample was expressed in terms of $\mathrm{IC}_{50}$ values, thus lower $\mathrm{IC}_{50}$ values indicated higher antioxidant capacity. The results suggested that the sprouts exposed to UV radiation i.e. $254 \mathrm{~nm}$ and $365 \mathrm{~nm}$ exhibited lower IC 50 values than that of control indicating enhancement of antioxidant activity by UV exposure. A similar trend was observed in the case of ABTS assay. A strong positive correlation was observed between ABTS and DPPH assays with a Pearson correlation coefficient of $r=0.653$ (table 1).

The reducing capacity of a plant sample acts as a significant indicator of its antioxidant potential. In the reducing power assay, the antioxidants convert the oxidized form of iron $\left(\mathrm{Fe}^{+3}\right)$ from ferric to ferrous $\left(\mathrm{Fe}^{+2}\right)$ state [14]. The reducing ability of the sprouts was expressed in correspondence to ascorbic acid equivalence. The Higher ascorbic acid equivalent value of extract indicated higher reducing capacity. It was observed that the sprouts treated with UV radiation showed enhanced reducing activity with higher ascorbic acid equivalent value when compared to that of control.

Another essential antioxidative mechanism involves the chelation of transition of metal ions such as copper $\left(\mathrm{Cu}^{2+}\right)$ and ferrous ions $\left(\mathrm{Fe}^{2+}\right)$, which leads to prevention of these metal ions to participate in Fenton and Haber-Weiss reactions, ultimately inhibiting the generation of highly reactive hydroxyl radicals which are responsible for oxidative stress-mediated diseases [29]. The antioxidant compounds that are efficiently involved in ferrous ion chelation helps in the mobilization of iron molecules present in tissues by the formation of soluble, stable complexes that are eventually excluded along with excretory products [30]. Hence in recent times, the chelation therapy is widely implemented in the treatment of iron-related complications such as thalassemia which is characterized by overloaded iron in vital body organs. In the present work, the UV exposure resulted in the enhancement of the metal chelating capacity of fenugreek sprouts thus further enriching the nutraceutical property of the sprouts.

A significant correlation was found between the antioxidants properties and the phenolic compounds. The Pearson correlation coefficient obtained between phenol content and the IC 50 value of antioxidant assays namely DPPH, ABTS and metal chelating were found to be- $0.745,-0.643$ and- 0.516 respectively (table 1). In agreement with present findings, earlier studies have also reported such significant correlation between phenolics and antioxidant property $[29,31]$. Such high correlation between the phenolics and the various antioxidative assays indicates the active participation of these secondary metabolites in the prevention of oxidative stress mediated disorders.

The two very important enzymes of the digestive system, $\alpha$-amylase and $\alpha$-glucosidase are considered to be involved in the release of glucose molecules in the blood via starch breakdown. High sugar concentration in blood can cause diabetic complications in a human which directly affects the functioning of internal organs. Hence the inhibition of these enzymes is essential for minimizing the starch breakdown in order to reduce the postprandial hyperglycemic level [32]. The increased level of reactive oxygen species (ROS) has been associated with the degradation of pancreatic beta-cells leading to type 1 diabetes and the onset of type 2 diabetes by insulin resistance [33]. Therefore the antioxidant compounds which are an efficient scavenger of reactive oxygen species might play important role in controlling oxidative stress mediated diabetic complications. In the present work, the results revealed that the fenugreek sprouts treated with UV radiation at $365 \mathrm{~nm}$ exhibited a significant enhancement in the $\alpha$-amylase as well as $\alpha$-glucosidase inhibitory activity over control and other treated sprouts. Also, it was observed that the same set of sprouts (exposed to $365 \mathrm{~nm}$ ) had higher phenolic and flavonoids content. Similar to our findings, various other workers have also reported that phenolic-rich extract has shown the better capability to inhibit $\alpha$-amylase and $\alpha$-glucosidase activity $[33,34]$. Interestingly, the Pearson correlation coefficient analysis also revealed a highly positive correlation of $\alpha$-amylase and $\alpha$-glucosidase inhibitory activity with DPPH based antioxidant activity also with those of the phenolic contents of the sprouts. Polyphenolic compounds have long been recognized as a potent inhibitor of the digestive enzymes because of their capability to bind with these proteins. Several other authors have also shown the carbohydrate hydrolyzing enzyme inhibitory activity of the phenolic compounds in various plant samples [35]. Thus the enhancement in antioxidant and antidiabetic activity can be attributed to the increased in the polyphenolic content in response to UV exposure.

The major reactive forms of oxygen which mainly exist in the form of Singlet oxygen, superoxide radicals, hydrogen peroxide and hydroperoxide are considered to be the molecules with greater toxic potentials to plant tissues. UV radiation is known for the increase in production of these reactive oxygen species in cell system [36]. As a result, it was observed that the roots of the experimental sets which were treated under UV exposure showed significant accumulation of $\mathrm{H}_{2} \mathrm{O}_{2}$ and superoxide in the roots and showed darker stain than control thus, indicating that UV radiation leads to increase in production of these reactive molecules. The accumulation of such reactive oxygen molecules has been found to damage the membranes of the cell and organelles which leads to a loss in their functions. The damages and injuries of biological membranes due to peroxidation of polyunsaturated fatty acids are generally correlated with the accretion of malonaldehyde [18] which is also a marker of lipid peroxidation process. As a consequence, the membrane fluidity is altered and ultimately ion leakage occurs from the tissue. In agreement to an aforesaid statement, it was observed that the roots of the seedlings exposed to UV radiation reflected higher malonaldehyde (darker stain with Schiff's reagent) and imparted darker stain against Evan's blue thus indicating loss of plasma membrane integrity. Similar to our findings other workers have also reported a higher level of lipid peroxidation in cucumber leaves due to UV irradiation [37].

Plants have evolved various protective mechanisms for minimising such deleterious effects of these free radicals. Among these defence strategies, both enzymatic and non-enzymatic mechanisms are involved. The enzymatic defence comprises of the efficient antioxidant enzymes such as catalase, peroxidase, superoxide dismutase, polyphenol oxidase etc. [38]. In the present study, the native on gel analysis was performed for two important antioxidant enzymes namely, catalase and superoxide dismutase. Studying ROS metabolism related to UV exposure includes investigation of enzymatic components of the antioxidant system. It has also been reported that UV irradiation leads to enhancement in activity of the antioxidant system, as a defence mechanism [39]. 
The results obtained in the present study indicates a considerable increase in the catalase activity of the sprouts subjected to UV irradiation (UV $365 \mathrm{~nm}$ and Comb) which was clearly visible on the gel with an increase in the intensity of the catalase isozyme of UV treated sprouts. A similar trend was observed in the case of peroxidase isozyme pattern with seedlings exposed to UV $365 \mathrm{~nm}$ showing best result. The peroxidase enzymes are reported to utilise phenolic compounds as their co-substrate and this fact was further confirmed in the present work by the presence of high phenolic content in the sprouts treated with UV $365 \mathrm{~nm}$. Elevation in the catalase and peroxidase activity has also been observed by other workers in different plant samples under UV irradiation [40]. It can be suggested that the excess $\mathrm{H}_{2} \mathrm{O}_{2}$ production might have resulted in induced catalase as well as peroxidase activity in response to UV exposure.

It was observed that the intensity of the SOD isozymes was found to increase in the lane loaded with protein extracted from seedlings subjected to UV irradiation, which indicates an increase in the antioxidant activity of SOD enzyme. Also, the increase in the SOD activity might be attributed to the production of superoxide radical due to UV irradiation as earlier suggested by [41] in leaves of barley cultivar. Such concomitant elevation with SOD activity and removal of $\mathrm{H}_{2} \mathrm{O}_{2}$ resulted from dismutation of $\mathrm{O}_{2}$-indicates complementary role of catalase with SOD activity.

Plasma membrane-bound NOX is considered to be involved in the regulation of the antioxidant defence mechanism during stress condition in plants [42]. Therefore, in the present study, the NOX isozyme analysis was performed on a native gel and the obtained result demonstrated an increase in the intensity of the NOX isozyme bands, thus indicating overexpression of NOX during UV irradiation. NOX has been known to be responsible for the production of superoxide anion radical. Thus, it can be stated that the increase in NOX activity leads to increase in $\mathrm{O}_{2}$-production which further activates SOD activity which dismutase $\mathrm{O}_{2}$ to $\mathrm{H}_{2} \mathrm{O}_{2}$ which influxes in the cellular space further activating catalase and peroxidase to overcome the ROS production for removal of $\mathrm{H}_{2} \mathrm{O}_{2}$ molecules. Enhancement in the activity of these antioxidant enzymes might be an acclimatisation mechanism by the fenugreek seedlings to overcome oxidative stress imposed by UV irradiation.

\section{CONCLUSION}

In conclusion, when subjected to the UV exposure the fenugreek sprouts showed enhancement in the free radical scavenging capacity as well as anti-diabetic activity. It can be suggested that the induction of NOX enzyme by UV exposure which is responsible for the production of $\mathrm{O}_{2}$-has resulted in the activation of SOD, which further dismutates $\mathrm{O}_{2}$ to $\mathrm{H}_{2} \mathrm{O}_{2}$. The increase in the production of $\mathrm{O}_{2}$. and $\mathrm{H}_{2} \mathrm{O}_{2}$ has been evident in the histochemical detection, thus increase in $\mathrm{H}_{2} \mathrm{O}_{2}$ concentration might resulted in overexpression of catalase and peroxidase activity. Since peroxidase is known to utilise phenolic compounds as a substrate, the observed enhancement of peroxidase activity might also be due to increase in phenolic contents in the sprouts during UV exposure. Further, it can be explained that the increase in the phenolic compounds was found to be responsible for the enhancement in antioxidant and antidiabetic properties of sprouts. These findings suggest that UV irradiation technology can be used as a simple and cost effective method for the production of sprouts with enriched nutraceutical properties.

\section{ACKNOWLEDGEMENT}

The authors acknowledge the financial aid from Department of Science and Technology (DST) for this research work under INSPIRE Scheme.

\section{CONFLICT OF INTERESTS}

\section{Authors claim no conflict of Interest}

\section{REFERENCES}

1. Marton M, Mandoki Zs, Csapo-Kiss Zs, Csapo J. The role of sprouts in human nutrition. A review. Acta Univ Sapientiae Aliment 2010;3:81-117.

2. Valko M, Leibfritz D, Moncola J, Cronin MTD, Mazura M, Telser J. Free radicals and antioxidants in normal physiological functions and human disease. Int $\mathrm{J}$ Biochem Cell Biol 2007;39:44-84.

3. Ashwini AM, Majumdar M. Quantification of phytochemical contents and in vitro antioxidant activity of Exacum bicolor (Roxb.), an endemic medicinal plant. Int J Pharm Pharm Sci 2015;7:225-30.

4. Irshad M, Chaudhuri PS. Oxidant-antioxidant system: role and significance in human body. Indian J Exp Biol 2002;40:1233-9.

5. Jha S, Ghosal M, Gupta SK, Ghosh A, Mandal P. In vitro free radical scavenging potential of oligopeptides derived from wheat and mung bean. Int J Pharm Pharm Sci 2016;8:428-32.

6. Hayden MR, Tyagi SC. Is type 2 diabetes mellitus a vascular disease (atheroscleropathy) with hyperglycemia a late manifestation? The role of NOS, NO and redox stress. Cardiovasc Diebetol 2003;2:2-12.

7. Jaiswal J, Bhardwaj H, Srivastava S, Gautam H, Sharma S. Antidiabetic activity of methanolic extract of Calotropis gigantea seeds on stz induced diabetic rats. Int J Pharm Pharm Sci 2014;6:254-7.

8. Meghwal M, Goswami TK. A Review on the functional properties, nutritional content, medicinal utilization and potential application of fenugreek. J Food Process Technol 2012. Doi:10.4172/2157-7110.1000181.

9. Frohnmeyer H, Staiger D. Ultraviolet-B radiation-mediated response in plants: balancing damage and protection. Plant Physiol 2003;133:1420-8.

10. Charles MT, Kalantari S, Corcuff R, Arul J. Post-harvest quality and sensory evaluation of UV-treated tomato fruit. Acta Hort 2005;682:537-42.

11. Blois MS. Antioxidant determinations by the use of a stable free radical. Nature 1958;181:1199-1200.

12. Re R, Pellegrini N, Proteggente A, Pannala A, Yang M, RiceEvans C. Antioxidant activity applying an improved ABTS radical cation decolorization assay. Free Radical Biol Med 1999;26:1231.

13. Dinis TCP, Madeira VMC, Almeida LM. Action of phenolic derivates (acetaminophen, salicylate and 5-aminosalycilate) as inhibitors of membrane lipid peroxidation and as peroxyl radical scavengers. Arch Biochem Biophys 1994;315:161-9.

14. Moein MR, Moein S, Ahmadizadeh S. Radical scavenging and reducing power of Salvia mirzayanii subfractions. Molecules 2008;13:2804-13.

15. Keles A, Koca I, Genccelep H. Antioxidant properties of wild edible mushrooms. J Food Process Technol 2011;2:130-6.

16. Dewanto V, Wu X, Adom KK, Liu RH. Thermal processing enhances the nutritional value of tomatoes by increasing total antioxidant activity. J Agric Food Chem 2002;50:3010-4.

17. Ghosal $\mathrm{M}$, Mandal P. In vitro antidiabetic and antioxidant activity of Calamus erectus Roxb. fruit: a wild plant of Darjeeling Himalaya. Int J Pharm Biol Sci 2013;4:671-84.

18. Gupta SK, Mandal P. Free radical scavenging activity and histochemical localisation of reactive oxygen species in fenugreek sprouts primed with nitric oxide donors. Am J Phytomed Clin Ther 2014;2:1310-22.

19. Kaur S, Singh HP, Batish DR, Kohli RK. Artemisia scoparia essential oil inhibited root growth involves reactive oxygen species (ROS)-mediated disruption of oxidative metabolism: in vivo ROS detection and alterations in antioxidant enzymes. Biochem Sys Ecol 2012;44:390-9.

20. Pereira GJG, Molina SMG, Lea PJ, Azevdo RA. Activity of antioxidant enzymes in response to cadmium in Crotalaria juncea. Plant Soil 2002;239:123-32.

21. Verma S, Dubey RS. Lead toxicity induces lipid peroxidation and alters the activities of antioxidant enzymes in growing rice plants. Plant Sci 2003;164:645-55.

22. Janda T, Szalai G, Tari I, Paldi E. Hydroponic treatment with salicylic acid decreases the effects of chilling injury in maize (Zea mays L.) plants. Planta 1999;208:175-80.

23. Frahry G, Schopfer P. NADH-stimulated, cyanide-resistant superoxide production in maize coleoptiles analyzed with a tetrazolium-based assay. Planta 2001;212:175-83.

24. Kalidhasan N, Bhagavan NB, Kannan ND. Ultraviolet-B (280$320 \mathrm{~nm}$ ) enhanced radiation-induced changes in secondary 
metabolites and photosystem-II of medicinal plant Withania somnifera Dunal. J Med Plant Res 2013;7:3112-20.

25. Alothman M, Bhat R, Karim A. Effects of radiation processing on phytochemicals and antioxidants in plant produce. Trends Food Sci Technol 2009;20:201-12.

26. Rozema J, Bjorn LO, Bornman JF, Gaberscik A, Hader DP, Trost $\mathrm{T}$, et al. The role of UV-B radiation in aquatic and terrestrial ecosystems-an experimental and functional analysis of the evolution of UV-absorbing compounds. J Photochem Photobiol B 2002;66:2-12.

27. Gonzalez-Aguilar GA, Zavaleta-Gatica R, Tiznado-Hernandez ME. Improving the postharvest quality of mango 'Haden' by UVC treatment. Postharvest Biol Technol 2007;45:108-16.

28. Neto CC, Amoroso JW, Liberty AM. Anticancer activities of cranberry phytochemicals: an update. Mol Nutr Food Res 2008;52:18-27.

29. Ghosal M, Chhetri PK, Ghosh MK, Mandal P. Changes in antioxidant activity of Cyphomandra betacea (Cav.) Sendtn. fruits during maturation and senescence. Int J Food Prop 2013;16:1552-64

30. Shinar E, Rachmilewitz EA. Oxidation denaturation of red blood cells in thalassemia. Semin Hematol 1990;27:70-91.

31. Gupta SK, Ghosal M, Choudhury D, Mandal P. Dynamic changes in antioxidant activity during floral development of Couroupita guianensis. Br J Pharm Res 2014;4:676-94.

32. Tarling CA, Woods K, Brastianos HC, Zhang R, Brayer GD, Andersen RJ, et al. The search for novel human pancreatic $\alpha-$ amylase inhibitors: high-throughput screening of terrestrial and marine natural product extracts. Chem Biochem 2008;9:433-8.

33. Saravanan S, Parimelazhagan T. In vitro antioxidant, antimicrobial and anti-diabetic properties of polyphenols of Passiflora ligularis Juss. fruit pulp. Food Science and Human Wellness 2014;3:56-64.
34. Shobana S, Sreerama YN, Malleshi N. Composition and enzyme inhibitory properties of finger millet (Eleusine coracana L.) seed coat phenolics: mode of inhibition of $\alpha$-glucosidase and pancreatic amylase. Food Chem 2009;115:1268-73.

35. Mai TT, Nghiem NT, Pham GT, Nguyen VC. Alpha-glucosidase inhibitory and antioxidant activities of Vietnamese edible plants and their relationships with polyphenol contents. J Nutr Sci Vitaminol 2007;53:267-76.

36. Bowler C, Van M, Inze MD. Superoxide dismutase and stress tolerance. Ann Rev Plant Physiol Plant Mol Biol 1992;43:83-116.

37. Kramer GF, Norman HA, Krizek DT, Mirechi RM. Oxidation and membrane lipids on cucumber. Phytochemisty 1991;30:2101-18.

38. Reshmi GR, Rajalakshmi R. Drought and UV stress response in Spilanthes acmella Murr., (tooth-ache plant). J Stress Physiol Biochem 2012;8:110-29.

39. Hideg E, Jansen MAK, Strid A. UV-B exposure, ROS, and stress: inseparable companions or loosely linked associates? Trends Plant Sci 2013;18:107-15.

40. Balakrishnan V, Venkatesan K, Ravindran KC, Kulandaivelu G. Protective mechanism in UV-B treated Crotalaria juncea L. seedlings. Plant Protect Sci 2005;41:115-20.

41. Abdel Nasser LEA. Effects of UV-B radiation on some physiological and biochemical aspects in two cultivars of barley (Hordeum vulgare L.). Egypt J Biol 2001;3:97-105.

42. Jiang MY, Zhang JH. Involvement of plasma membrane NADPH oxidase in abscisic acid-and water stress-induced antioxidant defense in leaves of maize seedlings. Planta 2002;215:1022-30.

\section{How to cite this article}

- Saran Kumar Gupta, Najnin Islam, Chandrani Choudhuri, Palash Mandal. Elicitation of therapeutic potential and oxidative stress assessment of fenugreek sprouts under uv irradiation. Int J Pharm Pharm Sci 2017;9(5):91-99. 